УДК 550.47

\title{
ГОДОВЫЕ КОЛЬЦА СОСНЫ ОБЫКНОВЕННОЙ (PINUS SYLVESTRIS L.) - ИНДИКАТОР ГЕОХИМИЧЕСКОЙ ОБСТАНОВКИ И ХРОНОЛОГИЧЕСКОГО ИЗМЕНЕНИЯ ХИМИЧЕСКОГО ЭЛЕМЕНТНОГО СОСТАВА ОКРУЖАЮЩЕЙ СРЕДЫ
}

\author{
Миронова Анастасия Сергеевна 1 , \\ asm2@tpu.ru
}

\author{
Рихванов Леонид Петрович 1 , \\ rikhvanov@tpu.ru
}

Барановская Наталья Владимировна',
nata@tpu.ru

\author{
Судыко Александр Фёдорович1, \\ sudykoAF@yandex.ru \\ 1 Национальный исследовательский Томский политехнический университет, \\ Россия, 634050, г. Томск, пр. Ленина, 30.
}

\begin{abstract}
Актуальность исследования обусловлена необходимостью поиска или изобретения точного и информативного индикатора для проведения экологического мониторинга окружающей среды.

Цель: изучить особенности накопления 28 химических элементов в годовых кольцах сосны обыкновенной (Pinus sylvestris L.) различных территорий.

Объект: годовые кольца сосны обыкновенной (Pinus sylvestris L).

Методы: отбор кернов сосны обыкновенной; высушивание и разделение проб на временные интервалы, измельчение кернов; определение содержания 28 химических элементов методом количественного инструментального нейтронноактивационного анализа; обработка данных статистическими методами.

Результаты. Определен химический элементный состав образцов годовых колец сосны обыкновенной (Pinus sylvestris L.), отобранных на территориях трех регионов России: Томской области, Кемеровской области и Республики Бурятия. Сравнение химического элементного состава годовых колец деревьев разных регионов помогло увидеть геохимические особенности каждой территории в отдельности. Специфичными для дерева Томской области являются элементы Ва (3 м2/к2), $R b(0,5$ мг/к2), Ce (0,02 мг/к2), Cs (0,01 мг/к2) и другие. Для дерева Кемеровской области: $\mathrm{Cr}(1 \mathrm{~m} / / \kappa 2), \mathrm{Fe}(34 \mathrm{m2} / к 2)$, As (0,01 мг/к2), Sb (0,002 мг/к2), La (0,01 мг/к2), U (0,004 мг/к2) и другие. Для дерева из Республики Бурятия: $\mathrm{Br}(1 \mathrm{m2} / к 2)$, $\mathrm{Sr}$ (7 мг/к2), Ag (0,04 мг/к2), Аu (0,001 мг/к2), Th (0,001 мг/кг) и другие. Таким образом, дендрогеохимический метод исследования может быть использован для оценки геохимической обстановки территории по уровню накопления химических элементов в годовых кольцах дерева. Динамики поступления химических элементов в годовые кольца позволяют изучать историю трансформации химического элементного состава окружающей среды. Так, тренды железа и хрома для Pinus sylvestris Keмеровской области ярко отражают развитие черной металлургии, а тренды $\mathrm{As}, \mathrm{Ag}, \mathrm{Cs}, \mathrm{Sb}, \mathrm{U}, \mathrm{Sm}, \mathrm{Th}$ и $\mathrm{Br}$ - развитие угольной промьшиленности региона. Тренды щелочных металлов Rb, Cs, радиоактивного U и редкоземельных элементов $\mathrm{Nd}, \mathrm{Sm}, \mathrm{Eu}$ показали интенсивность воздействия в разные промежутки времени предприятий ядерно-топливного цикла и других предполагаемых источников на окружающую среду Томского района Томской области. Сделан вывод, что дендрогеохимический мониторинг может быть использован в целях исследования локальных и глобальных изменений окружающей среды и позволяет восстанавливать историю прошлого загрязнения.
\end{abstract}

Ключевые слова:

Годовые кольца деревьев, сосна обыкновенная, геохимия, дендрогеохимия, инструментальный нейтронно-активационный анализ.

\section{Введение}

Годовые кольца деревьев - это уникальный хронологический индикатор изменения состояния окружающей среды. По уровню накопления химических элементов в годовых кольцах дерева можно выявлять особенности геохимической обстановки территории. В настоящий момент на стыке дендрохронологии, дендроклиматологии и геохимии происходит становление нового научного направления - дендрогеохимии - учения о химическом элементном составе годовых колец деревьев.

Интерес к изучению химического элементного состава годовых колец деревьев в научном мире по- явился во второй половине XX в. (первые работы $[1,2])$. На данный момент существует большое количество исследований, связанных с наблюдением изменения тяжелых металлов, микроэлементов и макроэлементов [3-17], стабильных изотопов и радиоуглерода в древесных кольцах [18-20].

Проводя дендрогеохимические исследования, необходимо учитывать физиологические особенности дерева $[2,10]$ и природные факторы среды: почвенный покров, орографию территории, климат. Поглощение тяжелых металлов корневой системой дерева является сложным процессом, который зависит от рН почвы, её окислительно-восстановительного потен- 
циала и структуры, содержания в ней органического вещества и металлов [1-20].

Дендрогеохимические исследования постоянно показывают, что деревья чувствительны к антропогенному воздействию. Нарушение физиологических процессов дерева, по мнению многих исследователей $[8,10,16]$, зависит от расстояния от источника загрязнения, преобладающих ветров и орографии области.

Объектом настоящего исследования являются годовые кольца представителя хвойных пород деревьев - сосны обыкновенной (Pinus sylvestris L). Широкое распространение и устойчивость к воздействию неблагоприятных факторов позволяет отнести хвойные виды деревьев к наиболее подходящим в дендрогеохимических исследованиях.

Цели данной работы: изучить особенности накопления 28 химических элементов в годовых кольцах сосны обыкновенной (Pinus sylvestris L.) различных территорий произрастания и оценить эффективность годовых колец деревьев как индикатора изменения геохимического состава биосферы.

Задачи: 1) провести отбор проб и подготовить материал для анализа; 2) получить информацию о накоплении химических элементов в годовых кольцах деревьев; 3) выявить элементы-индикаторы, отражающие геохимию территории и историю трансформации окружающей среды.

\section{Материалы и методы}

Образцы годичных колец сосны обыкновенной (Pinus sylvestris L.) были отобраны с территории трех регионов России: Томской, Кемеровской областей и Республики Бурятия.

Первая точка (рис. 1) находится в Томской области, Томском районе, в 30 км юго-западней города Томска, вблизи поселка 86-й Квартал. Регион характеризуется производствами нефтехимической промышленности, теплоэнергетики и ядерно-топливного цикла. На территории Томского района угрозу для окружающей среды представляет Сибирский химический комбинат - завод по производству оружейного плутония и обогащенного урана. Со времени начала работы (1953 г.) на комбинате происходили аварии, которые привели к загрязнению окружающей среды радионуклидами [21]. Точка отбора проб - 86-й Квартал - удалена от промышленной зоны района в противоположную сторону от основного направления розы ветров.

Вторая точка (рис. 1) расположена в Кемеровской области, Чебулинском районе, в 50 км южнее города Мариинска. В данном районе в 1984 г. был проведен подземный ядерный взрыв «Кварц-4». Поступления радиоактивных веществ в окружающую среду не отмечалось, однако до настоящего дня сохраняется возможность разгерметизации полости взрыва [22]. Подстилающие породы в районе пробоотбора сложены гранитами Чебулинского комплекса позднепалеозойского возраста. По данным [23], породы обладают повышенной радиоактивностью и редкометальной специализацией, что находит отражение в химическом элементном составе некоторых природных сред. Для региона наблюдаются высокие содержания в природных компонентах серебра, мышьяка, брома и цезия, что может быть последствием влияния горнодобывающих и перерабатывающих предприятий Кемеровской области [23].

Третья территория (рис. 1) исследования расположена на Баргузино-Чевыркуйском перешейке озера Байкал, Республики Бурятия, на территории Забайкальского национального парка. Для участка пробоотбора характерно проявление активных геологических и рудообразующих процессов Байкальской рифтовой зоны. Кроме того, территория находится в пределах геохимической аномалии, обусловленной ее расположением в пределах Ангаро-Витимского гранитоидного батолита с выраженной радиогеохимической спецификой по Th и U [24].

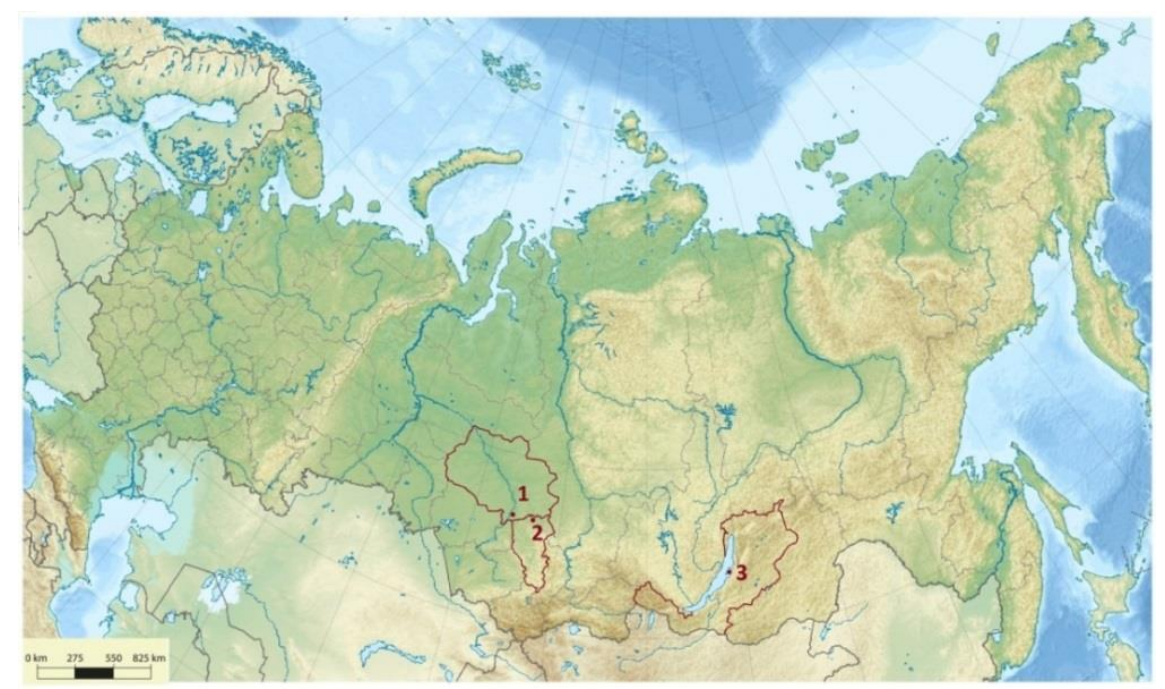

Puc. 1. Схема размещения отобранных для исследования проб сосны обыкновенной (Pinus sylvestris L.). Цифрами выделены места отбора проб в регионах: 1 - Томская область; 2 - Кемеровская область; 3 - Республика Бурятия

Fig. 1. Scheme of location of samples selected for the study of Pinus Sylvestris. The figures highlight the sampling sites in the regions: 1 -Tomsk region; 2 - Kemerovo region; 3 -Republic of Buryatia 


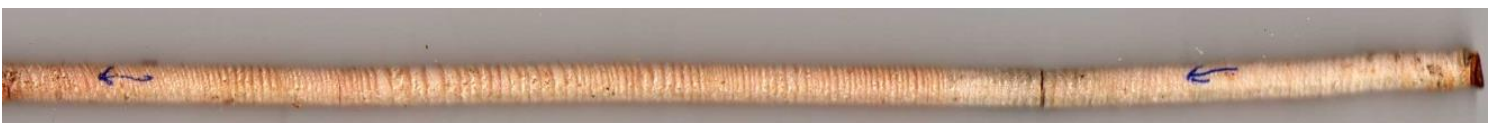

Pис. 2. Фотография возрастного керна сосны обыкновенной (Pinus sylvestris L.) из Республики Бурятия (справа кора; слева - сердиевина)

Fig. 2. Photo of Pinus Sylvestris age core sample from Republic of Buryatia (on the right - the bark; on the left - the heart of the tree)

Образцы древесины с живых деревьев были взяты с помощью возрастного бура (пример одного образца представлен на рис. 2), согласно методикам отбора и подготовки образцов древесины [25]. С каждой территории отбиралось по одному образцу. Диаметр высверленных кернов древесины 4-5 мм, длина 10-50 см. Керны отбирали на высоте 1,0-1,3 м от поверхности земли. Транспортировали собранные образцы древесины в специальном контейнере-тубусе, что исключало возможность их поломки. Образцы высушивались в сухом помещении до воздушно-сухого состояния. Для отчётливой видимости границ колец и клеток поверхность образца древесины была зачищена специальной бумагой. Зная точное календарное время взятия образца, методом обратного отсчёта (в направлении от периферии ствола к его центру) определялись календарные даты образования остальных колец.

Учитывая достаточно тонкие годовые кольца, не позволяющие однозначно интерпретировать их возраст и химический состав элементов отдельного годового кольца $[2,11,14]$, керны были разделены на сегменты - группы годовых колец. Образец с территории Кемеровской области был разделен на временные интервалы (годы): 1930-1944, 1945-1948, 1949-1955, 1956-1962, 1963-1969, 1970-1979, 1980-1989, 1990-1999, 2000-2008, 2009-2012; Томской области: 1890-1899, 1900-1944, 1945-1948, 1949-1955, 1956-1962, 1963-1969, 1970-1979, 1980-1989, 1990-1999, 2000-2008, 2009-2012; и Республики Бурятия: 1780-1899, 1900-1944, 1945-1962, 1963-1979, 1980-2012.

Годичные кольца были проанализированы в аккредитованной (аттестат № POCC RU.0001.511901) ядерно-геохимической лаборатории методом ИНАА на исследовательском ядерном реакторе ИРТ-Т Национального исследовательского Томского политехнического университета по аттестованным методикам (НСАМ ВИМС № 410-ЯФ). В пробах были определены $\mathrm{Na}, \mathrm{Ca}, \mathrm{Sc}, \mathrm{Cr}, \mathrm{Fe}, \mathrm{Co}, \mathrm{Zn}, \mathrm{As}, \mathrm{Br}, \mathrm{Rb}, \mathrm{Sr}$, $\mathrm{Ag}, \mathrm{Sb}, \mathrm{Cs}, \mathrm{Ba}, \mathrm{La}, \mathrm{Ce}, \mathrm{Nd}, \mathrm{Sm}, \mathrm{Eu}, \mathrm{Tb}, \mathrm{Yb}, \mathrm{Lu}, \mathrm{Hf}, \mathrm{Ta}$, $\mathrm{Au}, \mathrm{Th}, \mathrm{U}$ (28 химических элементов). Результаты были обработаны статистическими методами с помощью пакета прикладных статистических программ.

\section{Результаты и обсуждение}

Сравнительная характеристика элементного состава сосны обыкновенной (Pinus sylvestris L.) различных регионов (мг/кг, сухое вещество) представлена в табл. 1.

На рис. 3 представлена диаграмма средних содержаний 28 химических элементов в соснах различных территорий произрастания.

Анализ диаграммы средних содержаний химических элементов в соснах различных территорий про- израстания показывает, что указанные регионы имеют свои геохимические особенности.

Сосна из Томской области относительно других деревьев характеризуется наибольшим содержанием рубидия $(0,5$ мг/кг), цезия $(0,01$ мг/кг), бария (3 мг/кг), церия $(0,02$ мг/кг), неодима $(0,01$ мг/кг), европия $(0,003$ мг/кг) и тантала $(0,001$ мг/кг).

В сосне из Кемеровской области отчётливо наблюдается обогащение древесины относительно деревьев других регионов хромом (1 мг/кг), железом (34 мг/кг), мышьяком (0,01 мг/кг), сурьмой $(0,002$ мг/кг), лантаном $(0,01$ мг/кг), самарием $(0,0002$ мг/кг), лютецием $(0,0002$ мг/кг) и ураном $(0,004$ мг/кг).

Древесина сосны Республики Бурятия отличается высокими содержаниями брома (1 мг/кг), стронция

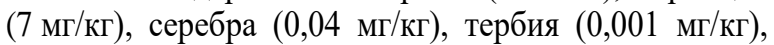
иттербия $(0,0004 \mathrm{мг} / \kappa г)$, гафния $(0,0005$ мг/кг), золота $(0,001 \mathrm{мг} / к г)$ и тория $(0,001 \mathrm{мг} / \mathrm{кг})$.

Сравнительный анализ помогает увидеть и определить геохимическую специфику территории произрастания дерева. Согласно классификации В.М. Гольдшмидта [26], для территории Кемеровской области характерна золото-уран-металлоидная ассоциация элементов. Таким образом, мышьяк и уран в древесных кольцах, можем предположить, имеют природный источник поступления, связанный с геохимией территории. Для Томского региона характерна редкометалльно-редкоземельная ассоциация. Избыточное концентрирование в них редких щелочей и некоторых лантаноидов (Ce, $\mathrm{Nd}$ и $\mathrm{Eu})$, скорее всего, имеет техногенное происхождение. Геохимическая ассоциация, выявляемая на юго-западном побережье Байкала, достаточно неоднородная. Высокое содержание $\mathrm{Sr}, \mathrm{Tb}, \mathrm{Yb}, \mathrm{Hf}, \mathrm{Th}$ в годовых кольцах сосны Республики Бурятия, вероятнее всего, является отражением геохимических особенностей гранитоидов территории, а повышенные концентрации $\mathrm{Br}, \mathrm{Ag}, \mathrm{Au}$ связаны с «дыханием» Байкальской рифтовой зоны.

В табл. 2 химические элементы разделены на группы в зависимости от их среднего содержания в дереве.

Для вида Pinus sylvestris L. отмечаются химические элементы, которые вне зависимости от территории произрастания дерева имеют приблизительно одинаковые уровни накопления: кальций, железо, натрий, цинк, стронций, барий (>1 мг/кг); рубидий, кобальт $(0,1-1$ мг/кг); серебро, церий $(<0,1-0,01 \mathrm{мг} / \kappa г)$; сурьма, европий, тантал $(<0,01-0,001 \mathrm{мг} / \kappa \Gamma)$; скандий, иттербий, лютеций, самарий $(<0,001$ мг/кг). Преобладание по своему содержанию в древесине $\mathrm{Ca}, \mathrm{Fe}, \mathrm{Na}, \mathrm{Zn}, \mathrm{Sr}$ и $\mathrm{Ba}$ можно объяснить высокой значимостью данных химических элементов для растений вида Pinus sylvestris $L$. 
Известия Томского политехнического университета. Инжиниринг георесурсов. 2020. Т. 331. № 1. 106-116

Миронова А.С. и др. Годовые кольца сосны обыкновенной (Pinus sylvestris L.) - индикатор геохимической обстановки и ...

Таблица 1. Среднее содержание химических элементов в соснах (Pinus sylvestris L.) различных территорий произрастания

Table 1. Average content of chemical elements in pines (Pinus sylvestris L.) of different growing areas

\begin{tabular}{|c|c|c|c|}
\hline $\begin{array}{c}\text { Химические } \\
\text { элементы, мг/кг } \\
\text { Chemical } \\
\text { elements, } \mathrm{mg} / \mathrm{kg}\end{array}$ & $\begin{array}{c}\text { Томская обл, среднее } \pm \text { стандартная } \\
\text { ошибка/min-max (11 проб) } \\
\text { Tomsk region, mean } \pm \text { standard } \\
\text { error/min-max (11 samples) }\end{array}$ & $\begin{array}{l}\text { Кемеровская обл, среднее } \pm \text { стан- } \\
\text { дартная ошибкка/min-max (10 проб) } \\
\text { Kemerovo region, mean } \pm \text { standard } \\
\text { error/min-max (10 samples) }\end{array}$ & $\begin{array}{c}\text { Республика Бурятия, среднее } \pm \text { стан- } \\
\text { дартная ошибка/min-max (5 проб) } \\
\text { Republic of Buryatia, mean } \pm \text { standard } \\
\text { error/min-max (5 samples) }\end{array}$ \\
\hline 1 & 3 & 2 & 4 \\
\hline $\mathrm{Na}$ & $\frac{6 \pm 1}{4-9}$ & $\frac{15 \pm 1}{9-23}$ & $\frac{11 \pm 3}{2-16}$ \\
\hline $\mathrm{Ca}$ & $\frac{894 \pm 71}{607-1249}$ & $\frac{651 \pm 33}{459-824}$ & $\frac{484 \pm 25}{391-542}$ \\
\hline $\mathrm{Sc}$ & $\frac{0,0004 \pm 0,0001}{0,0001-0,001}$ & $\frac{0,0004 \pm 0,00003}{0,0002-0,002}$ & $\frac{0,0004 \pm 0,00003}{0,0003-0,0005}$ \\
\hline $\mathrm{Cr}$ & $\frac{0,3 \pm 0,06}{0,03-1}$ & $\frac{1 \pm 0,1}{0,3-1}$ & $\frac{0,3 \pm 0,1}{0,2-1}$ \\
\hline $\mathrm{Fe}$ & $\frac{7 \pm 2}{0,1-19}$ & $\frac{34 \pm 6}{14-60}$ & $\frac{7 \pm 2}{1-13}$ \\
\hline Co & $\frac{0,1 \pm 0,01}{0,04-0,1}$ & $\frac{0,1 \pm 0,02}{0,04-0,1}$ & $\frac{0,1 \pm 0,003}{0,1-0,1}$ \\
\hline $\mathrm{Zn}$ & $\frac{8 \pm 1}{5-11}$ & $\frac{8 \pm 0,2}{6-9}$ & $\frac{8 \pm 1}{6-9}$ \\
\hline As & $\frac{0,001 \pm 0,0003}{0,0004-0,003}$ & $\frac{0,01 \pm 0,003}{0,0004-0,02}$ & $\frac{0,0004 \pm 0}{0,0004-0,0004}$ \\
\hline $\mathrm{Br}$ & $\frac{0,2 \pm 0,03}{0,1-0,4}$ & $\frac{0,3 \pm 0,04}{0,1-0,5}$ & $\frac{1 \pm 0,01}{1-1}$ \\
\hline $\mathrm{Rb}$ & $\frac{0,5 \pm 0,1}{0,1-1}$ & $\frac{0,3 \pm 0,04}{0,1-1}$ & $\frac{0,3 \pm 0,04}{0,2-0,4}$ \\
\hline $\mathrm{Sr}$ & $\frac{3 \pm 1}{0,3-7}$ & $\frac{3 \pm 0,3}{0,3-4}$ & $\frac{7 \pm 0,3}{6-8}$ \\
\hline $\mathrm{Ag}$ & $\frac{0,02 \pm 0,01}{0,001-0,1}$ & $\frac{0,03 \pm 0,004}{0,01-0,1}$ & $\frac{0,04 \pm 0,01}{0,001-0,1}$ \\
\hline $\mathrm{Sb}$ & $\frac{0,002 \pm 0,0004}{0,0003-0,003}$ & $\frac{0,002 \pm 0,001}{0,001-0,01}$ & $\frac{0,002 \pm 0,0004}{0,001-0,003}$ \\
\hline Cs & $\frac{0,01 \pm 0,002}{0,002-0,01}$ & $\frac{0,01 \pm 0,001}{0,002-0,01}$ & $\frac{0,004 \pm 0,001}{0,001-0,01}$ \\
\hline $\mathrm{Ba}$ & $\frac{3 \pm 0,3}{1-4}$ & $\frac{2 \pm 0,2}{1-3}$ & $\frac{2 \pm 0,1}{1-2}$ \\
\hline $\mathrm{La}$ & $\frac{0,003 \pm 0,0002}{0,001-0,004}$ & $\frac{0,01 \pm 0,001}{0,002-0,01}$ & $\frac{0,003 \pm 0,001}{0,001-0,004}$ \\
\hline $\mathrm{Ce}$ & $\frac{0,02 \pm 0,004}{0,002-0,04}$ & $\frac{0,01 \pm 0,003}{0,01-0,03}$ & $\frac{0,01 \pm 0,001}{0,005-0,01}$ \\
\hline $\mathrm{Nd}$ & $\frac{0,01 \pm 0,002}{0,003-0,02}$ & $\frac{0,004 \pm 0,0005}{0,003-0,01}$ & $\frac{0,005 \pm 0,002}{0,003-0,01}$ \\
\hline $\mathrm{Sm}$ & $\frac{0,0002 \pm 0,00004}{0,0001-0,001}$ & $\frac{0,0002 \pm 0,0001}{0,0001-0,001}$ & $\frac{0,0002 \pm 0,0001}{0,0001-0,001}$ \\
\hline $\mathrm{Eu}$ & $\frac{0,003 \pm 0,001}{0,001-0,01}$ & $\frac{0,002 \pm 0,0003}{0,001-0,004}$ & $\frac{0,001 \pm 0,0003}{0,0003-0,002}$ \\
\hline $\mathrm{Tb}$ & $\frac{0,0004 \pm 0,0002}{0,00004-0,001}$ & $\frac{0,0001 \pm 0,00002}{0,00004-0,0002}$ & $\frac{0,001 \pm 0,0002}{0,00004-0,001}$ \\
\hline $\mathrm{Yb}$ & $\frac{0,0003 \pm 0,0001}{0,00003-0,001}$ & $\frac{0,0001 \pm 0,00002}{0,00003-0,0002}$ & $\frac{0,0004 \pm 0,0002}{0,00003-0,001}$ \\
\hline $\mathrm{Lu}$ & $\frac{0,0002 \pm 0,0001}{0,0001-0,001}$ & $\frac{0,0002 \pm 0,00003}{0,0001-0,0004}$ & $\frac{0,0001 \pm 0,00005}{0,00003-0,0002}$ \\
\hline $\mathrm{Hf}$ & $\frac{0,0001 \pm 0,00004}{0,0001-0,001}$ & $\frac{0,0001 \pm 0,00003}{0,00003-0,0003}$ & $\frac{0,0005 \pm 0,0004}{0,00003-0,002}$ \\
\hline $\mathrm{Ta}$ & $\frac{0,001 \pm 0,0002}{0,0001-0,002}$ & $\frac{0,001 \pm 0,0002}{0,0001-0,001}$ & $\frac{0,0003 \pm 0,0002}{0,0001-0,001}$ \\
\hline $\mathrm{Au}$ & $\frac{0,0004 \pm 0,0001}{0,0001-0,001}$ & $\frac{0,0003 \pm 0,0001}{0,0001-0,001}$ & $\frac{0,001 \pm 0,0002}{0,0005-0,002}$ \\
\hline Th & $\frac{0,0005 \pm 0,0002}{0,0001-0,002}$ & $\frac{0,0003 \pm 0,0001}{0,0001-0,001}$ & $\frac{0,001 \pm 0,0001}{0,0001-0.001}$ \\
\hline $\mathrm{U}$ & $\frac{0,002 \pm 0,001}{0,0002-0,01}$ & $\frac{0,004 \pm 0,001}{0,0002-0,01}$ & $\frac{0,003 \pm 0,0004}{0,003-0,005}$ \\
\hline
\end{tabular}


Известия Томского политехнического университета. Инжиниринг георесурсов. 2020. Т. 331. № 1. 106-116

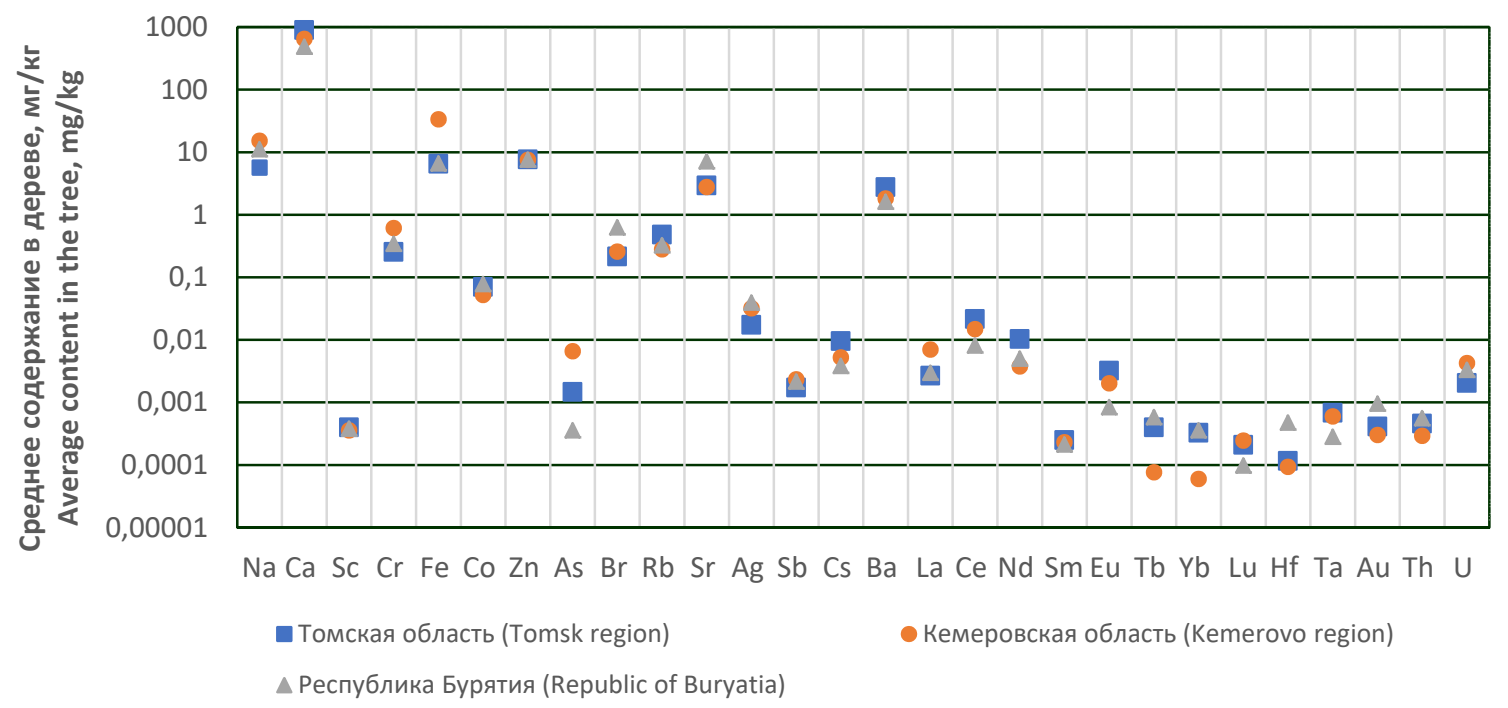

Pис. 3. Средние содержания химических элементов в сосне обыкновенной (Pinus sylvestris L.)

Fig. 3. Average content of chemical elements in Scots pine (Pinus sylvestris L.)

Таблица 2. Группы химических элементов по диапазонам средних содержаний в соснах (Pinus sylvestris L.) различных территорий произрастания

Table 2. Groups of chemical elements in the ranges of mean contents in pines (Pinus sylvestris L.) of different areas of growth

\begin{tabular}{|c|c|c|c|c|c|}
\hline \multirow{2}{*}{$\begin{array}{l}\text { Место отбора образца } \\
\text { Sampling location }\end{array}$} & \multicolumn{5}{|c|}{$\begin{array}{l}\text { Диапазон средних содержаний химических элементов в дереве (мг/кг) } \\
\text { Range of average contents of chemical elements in the tree }(\mathrm{mg} / \mathrm{kg})\end{array}$} \\
\hline & $>1$ & $0,1-1$ & $<0,1-0,01$ & $<0,01-0,001$ & $<0,001$ \\
\hline $\begin{array}{l}\text { Томская область } \\
\text { Tomsk region }\end{array}$ & $\begin{array}{l}\mathrm{Ca}, \mathrm{Zn}, \mathrm{Fe}, \mathrm{Na}, \mathrm{Sr}, \\
\mathrm{Ba}\end{array}$ & $\mathrm{Rb}, \mathrm{Cr}, \mathrm{Br}, \mathrm{Co}, \mathrm{Nd}$ & $\mathrm{Ag}, \mathrm{Ce}, \mathrm{Cs}$ & As, Eu, La, U, Sb, Ta, Tb & $\begin{array}{l}\mathrm{Au}, \mathrm{Hf}, \mathrm{Th}, \mathrm{Sc} \\
\mathrm{Yb}, \mathrm{Sm}, \mathrm{Lu}\end{array}$ \\
\hline $\begin{array}{l}\text { Кемеровская область } \\
\text { Kemerovo region }\end{array}$ & $\begin{array}{l}\mathrm{Ca}, \mathrm{Fe}, \mathrm{Na}, \mathrm{Zn}, \mathrm{Sr}, \\
\mathrm{Ba}, \mathrm{Cr}\end{array}$ & $\mathrm{Rb}, \mathrm{Br}, \mathrm{Co}$ & As, Ag, Ce, U, La, Cs & $\mathrm{Sb}, \mathrm{Nd}, \mathrm{Eu}, \mathrm{Ta}, \mathrm{Th}$ & $\begin{array}{l}\mathrm{Sc}, \mathrm{Tb}, \mathrm{Au}, \mathrm{Yb} \\
\mathrm{Lu}, \mathrm{Sm}, \mathrm{Hf}\end{array}$ \\
\hline $\begin{array}{l}\text { Республика Бурятия } \\
\text { Republic of Buryatia }\end{array}$ & $\begin{array}{c}\mathrm{Ca}, \mathrm{Na}, \mathrm{Zn}, \mathrm{Sr}, \mathrm{Fe}, \\
\mathrm{Ba}, \mathrm{Br}\end{array}$ & $\mathrm{Cr}, \mathrm{Rb}, \mathrm{Co}$ & $\mathrm{Ag}, \mathrm{Nd}, \mathrm{Ce}, \mathrm{As}$ & $\begin{array}{l}\mathrm{Tb}, \mathrm{Cs}, \mathrm{U}, \mathrm{La}, \mathrm{Sb}, \mathrm{Eu}, \mathrm{Au}, \\
\text { Ta, Hf, Th }\end{array}$ & $\mathrm{Sc}, \mathrm{Yb}, \mathrm{Sm}, \mathrm{Lu}$ \\
\hline
\end{tabular}

Уровни накопления $\mathrm{Cr}, \mathrm{Br}, \mathrm{As}, \mathrm{U}, \mathrm{La}, \mathrm{Cs}, \mathrm{Nd}$, Th, $\mathrm{Tb}, \mathrm{Au}$ и Hf неодинаковы для деревьев вида Pinus sylvestris L. различных регионов. Можем предположить, что данные химические элементы будут являться индикаторами, отражающими специфику (природного или антропогенного характера) территории произрастания дерева.

Отмечается, что группы элементов: $\mathrm{Ca}-\mathrm{Sr}-\mathrm{Ba} ; \mathrm{Fe}-\mathrm{Cr}$ и $\mathrm{Co}-\mathrm{Zn}$, имеют приблизительно одинаковые динамики накопления в древесных кольцах, вне зависимости от территории произрастания дерева (рис. 4-7). Это, скорее всего, обусловлено участием данных химических элементов в схожих физиологических процессах, а также может указывать на единую природу: общий источник, форму и путь поступления элементов в организм дерева.

Кальций, стронций и барий выполняют функцию цементирования клеточных стенок, участвуют в ионном обмене клеток [27]. Железо и хром необходимы для производства хлорофилла, участвуют в процессе роста растения [27]. Цинк отвечает за метаболизм, фотосинтез и дыхание. Кобальт участвует в процессе фотосинтеза [27].

При интерпретации дендрогеохимической информации необходимо учитывать свойства каждого химического элемента, особенно их химическую актив- ность, которая может отразиться на правильности оценки динамики накопления химического элемента в годовых кольцах дерева. Предполагается, что элементы с высокой химической активностью: щелочные и щелочноземельные металлы ( $\mathrm{Na}, \mathrm{Ca}, \mathrm{Sr}, \mathrm{Ba})$ находятся в годовых кольцах дерева в виде ионов и не могут быть стабильны $[5,6,28]$. В свою очередь, $\mathrm{Fe}$ и $\mathrm{Zn}$ образуют прочные комплексы с аминокислотами в ксилеме дерева внутри одного кольца прироста и им не свойственна миграция в соседние годовые кольца [28].

Если принять одинаковые динамики накопления вышеуказанных химических элементов за закономерность, то отклонения в динамиках можно рассматривать как сбой, вызванный изменениями антропогенного или природного фактора.

Хром и железо - это элементы-индикаторы промышленных производств черной металлургии, машиностроения и металлообработки [29]. В годовых кольцах дерева Томской области с 1945 по 1980 гг. мы можем увидеть отклонения в синхронности накопления этих элементов (рис. 4). Известно, что в данный период времени вблизи поселка 86-й Квартал прокладывалась, эксплуатировалась для вывозки леca, a после демонтировалась узкоколейная железная дорога. Возможно, рассеяние химических элементов в 
результате такой деятельности повлияло на сбой в динамиках. Для дерева Кемеровской области также отмечается сбой в динамиках $\mathrm{Fe}-\mathrm{Cr}$ в 1956-1962 гг., что, возможно, связано с активной добычей и переработкой железной руды в Таштагольском районе области и дальним переносом-рассеиванием железа по территории региона.

На рис. 5 в динамиках для дерева Томской области проявляется отклонение цинка в 2000-2012 гг. Цинкэлемент-индикатор животноводческой сельскохозяйственной промышленности [29], интенсивное разви- тие которой в этот период в Томском районе могло отразиться на динамике накопления элемента.

Нами было отмечено почти идентичное повторение трендов кобальта и цинка бромом (рис. 5) для дерева Томской области. Бром также имеет схожую динамику с кобальтом и цинком для дерева Кемеровской области с выраженными пиками в периоды 1963-1969 гг., 1980-1989 гг. Причиной может являться сжигание местными жителями или небольшими предприятиями каменного угля Кузнецкого бассейна, который, как отмечено в работе [23], обогащен бромом.

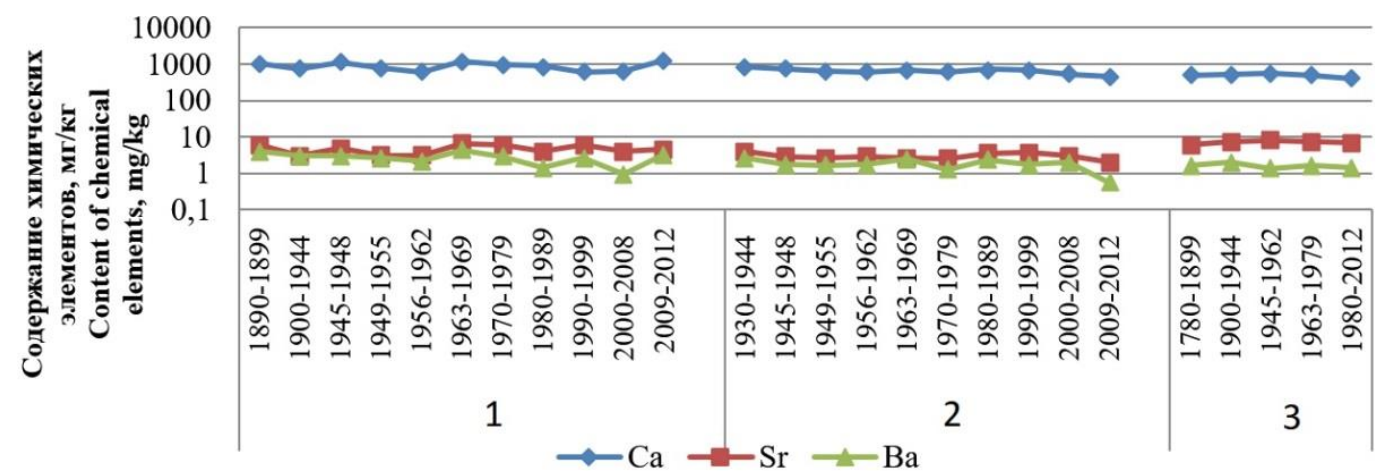

Puc. 4. Диаграммы накопления Ca, Sr, Ва в годовых кольцах сосны обыкновенной (Pinus sylvestris L.) разных регионов России: 1 - Томская область, 2 - Кемеровская область, 3 - Республика Бурятия

Fig. 4. Diagrams of $\mathrm{Ca}, \mathrm{Sr}, \mathrm{Ba}$ accumulation in annual rings of Scots pine (Pinus sylvestris L.) in different regions of Russia: 1 -Tomsk region, 2 - Kemerovo region, 3 - Republic of Buryatia

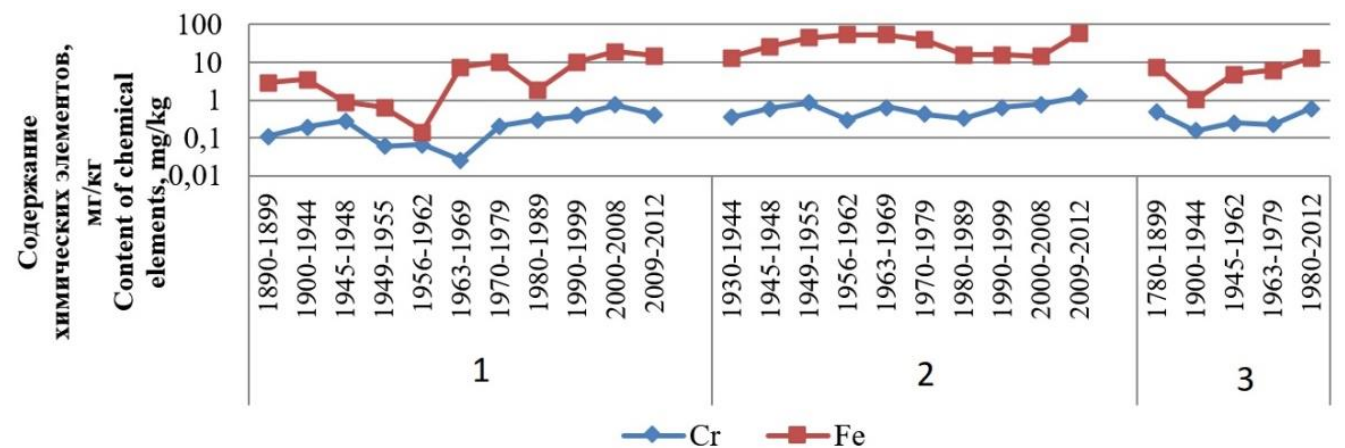

Pис. 5. Диаграммы накопления $\mathrm{Cr}$ и Fе в годовых кольцах сосны обыкновенной (Pinus sylvestris L.) paзных регионов России: 1 - Томская область, 2 - Кемеровская область, 3 - Республика Бурятия

Fig. 5. Diagrams of $\mathrm{Cr}$ and $\mathrm{Fe}$ accumulation in annual rings of Scots pine (Pinus sylvestris L.) in different regions of Russia: 1 - Tomsk region, 2 - Kemerovo region, 3 - Republic of Buryatia

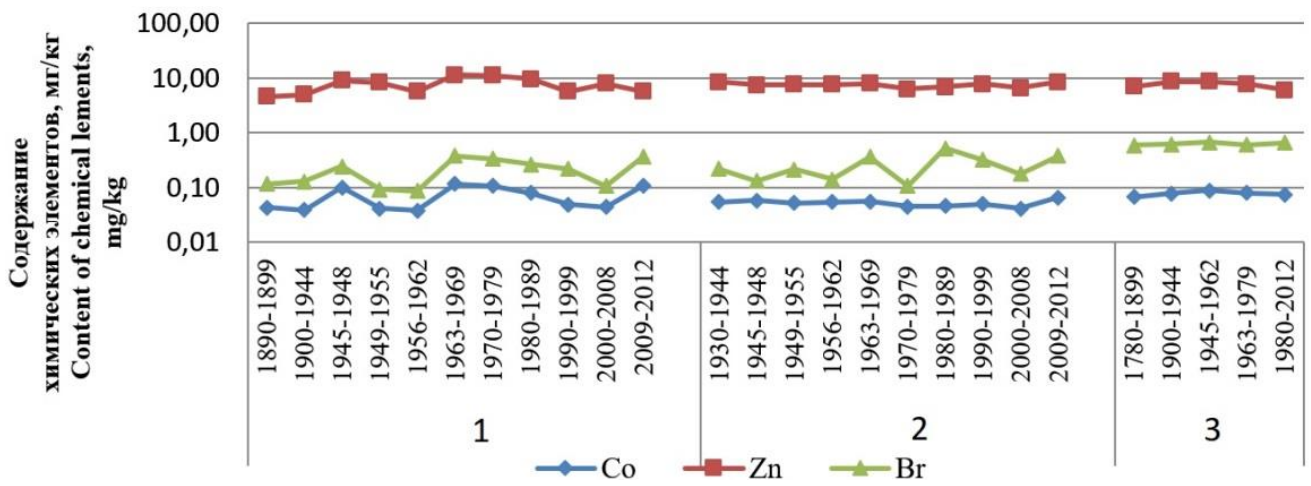

Pис. 6. Диаграммы накопления Co, Zn и Br в годовых кольцах сосны обыкновенной (Pinus sylvestris L.) paзныхх peгионов России: 1 - Томская область, 2 - Кемеровская область, 3 - Республика Бурятия

Fig. 6. Diagrams of Co, $\mathrm{Zn}, \mathrm{Br}$ accumulation in annual rings of Scots pine (Pinus sylvestris L.) in different regions of Russia: 1 - Tomsk region, 2 - Kemerovo region, 3 - Republic of Buryatia 


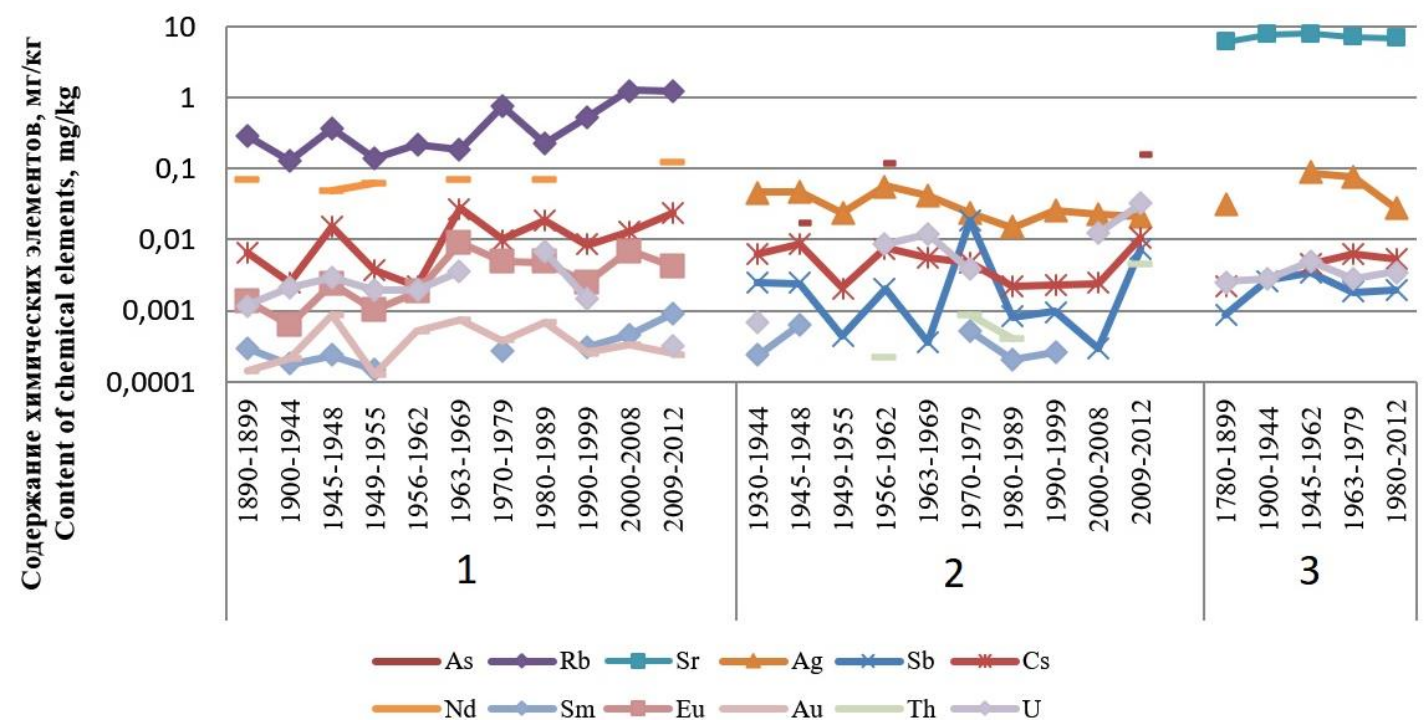

Pис. 7. Диаграммы накопления химических элементов в годовых кольцах сосны обыкновенной (Pinus sylvestris L.) разных регионов России: 1-Томская область, 2-Кемеровская область, 3-Республика Бурятия

Fig. 7. Diagrams of accumulation of chemical elements in annual rings of Scots pine (Pinus sylvestris L.) of different regions of Russia: 1 -Tomsk region, 2 -Kemerovo region, 3 -Republic of Buryatia

Интерпретация динамик химических элементов непростой процесс. Приходится рассматривать каждый химический элемент в отдельности, пытаясь найти группы элементов с одинаковыми динамиками или хотя бы с одинаковыми пиками их трендов. На рис. 5 элементы годовых колец сосны Томской области $\mathrm{Rb}, \mathrm{Nd}, \mathrm{Cs}, \mathrm{U}, \mathrm{Eu}, \mathrm{Au}, \mathrm{Sm}$ имеют некоторые совпадения трендов. Все динамики имеют высокие пики в 1945-1948 гг., в 1963-1969 гг. (кроме рубидия), в 1980-1989 гг. - только U, Cs, Nd, Eu и $\mathrm{Au}$, в 2000-2012 гг. - только Rb, Nd, Cs и Sm. Источниками, повлиявшими на активное накопление отмеченных химических элементов в названные отрезки времени, могли быть предприятия ядерно-топливного цикла Томского района, Новосибирский завод редких металлов, ядерные испытания СССР.

Элементы As, Ag, Cs, Sb, U, Sm, Th содержатся в золе каменных углей Кемеровской области. На рис. 5 для сосны данного региона показаны треки накопления этих элементов. Пики максимального поступления в окружающую среду и высокого накопления в древесине дерева цезия, самария, сурьмы и серебра приходятся на 1945-1948 и на 1956-1962 гг. Высокие пики сурьмы, урана, тория и самария отмечаются в 1970-1979 гг. Также высокий пик мышьяка, урана, цезия, сурьмы и тория приходится на 2009-2012 гг.

В годовых кольцах сосны Республики Бурятия (рис. 6) отмечается высокое накопление стронция, серебра, цезия, урана и сурьмы в 1945-1962 гг., что также может быть следствием выпадения радиоактивных осадков в дальних районах от проводившихся во времена СССР ядерных испытаний и [30].

\section{Заключение}

Сравнение химического элементного состава годовых колец деревьев разных регионов помогло уви- деть геохимические особенности каждой территории в отдельности. Специфичными для дерева Томской области были выявлены следующие элементы: Rb, Cs, $\mathrm{Ba}, \mathrm{Ce}, \mathrm{Nd}, \mathrm{Eu}$ и Та. Для дерева Кемеровской области: $\mathrm{Cr}, \mathrm{Fe}, \mathrm{As}, \mathrm{Sb}, \mathrm{La}, \mathrm{Sm}, \mathrm{Lu}$ и U. Для дерева Республики Бурятия: $\mathrm{Br}, \mathrm{Sr}, \mathrm{Ag}, \mathrm{Tb}, \mathrm{Yb}, \mathrm{Hf}, \mathrm{Au}$ и Th. Таким образом, дендрогеохимический метод исследования может быть использован для оценки геохимической обстановки территории по уровню накопления химических элементов в годовых кольцах дерева.

Динамики поступления химических элементов в годовые кольца позволяют изучать историю трансформации химического элементного состава окружающей среды. Так, тренды железа и хрома для сосны Кемеровской области ярко отражают развитие черной металлургии, а тренды As, Ag, Cs, Sb, U, Sm, Th и $\mathrm{Br}-$ развитие угольной промышленности региона. Тренды щелочных металлов Rb, Cs, радиоактивного $\mathrm{U}$ и редкоземельных элементов $\mathrm{Nd}, \mathrm{Sm}, \mathrm{Eu}$ показали интенсивность воздействия в разные промежутки времени предприятий ядерно-топливного цикла и других предполагаемых источников на окружающую среду Томского района Томской области.

На изменчивость химического элементного состава годовых колец дерева влияют следующие факторы:

1. Место отбора проб с природными и техногенными геохимическими особенностями, оказывающими влияние на изменение химического состава годичных колец.

2. Физиологические процессы растения, проявляющиеся как в количественной характеристике содержания элементов, так и в виде тенденций содержания определенных химических элементов в годовых кольцах дерева (кальций-стронцийбарий; хром-железо; кобальт-цинк). 
Таким образом, дендрогеохимический метод может быть использован в экологическом мониторинге в целях исследования локальных и глобальных изменений окружающей среды. Уникальность метода заключается в воз-

\section{СПИСОК ЛИТЕРАТУРЫ}

1. Ault W.U. Senechal R.G., Erlebach W.E. Isotopic composition as a natural tracer of lead in the environment // Environmental Science \& Technology. - 1970. - № 4. - P. 305-313.

2. Tout R.E., Gilboy W.B., Spyrou N.M. Neutron activation studies of trace elements in tree rings // Journal of Radioanalytical Chemistry. - 1977. - № 37. - P. 705-715.

3. Дендрогеохимические особенности ископаемой лиственницы (урочище Пазырык) и современных лиственниц Горного Алтая / Л.П. Рихванов, Ю.В. Робертус, А.С. Миронова Ф.Б. Бакшт, А.Ф. Судыко // Известия Томского политехнического университета. Инжиниринг георесурсов. - 2017. Т. 328. - № 6. - С. 108-119.

4. Дендрогеохимическая индикация трансграничных переносов экотоксикантов на территорию Алтая / Ю.В. Робертус Л.П. Рихванов, Р.В. Любимов // Известия Томского политехнического университета. - 2010. - Т. 317. - № 1. - С. 173-177.

5. Методология получения 600 -летней многоэлементной летописи на основе годичных колец лиственницы с полуострова Таймыр, Россия / А.М. Грачев, Е.А. Ваганов, С.У. Левитт, И.П. Панюшкина, Е.П. Чебыкин, В.В. Шишов, Н.А. Жученко, А.А. Кнорре, М.К. Хьюз, М.М. Наурзбаев // Журнал Сибирского федерального университета. Серия: Биология. 2013. - Т. 6. - № 1. - С. 61-72.

6. Динамика содержания зольных элементов в годичных слоях старовозрастных сосен, произрастающих в пойменных биотопах / Ю.П. Демаков, С.М. Швецов, В.И. Таланцев, К.К. Калинин // Вестник МарГТУ. - 2011. - № 3. - С. 25-35.

7. Hristovski S., Melovski L. Radial patterns of 13 elements in the tree rings of beech trees from Mavrovo national park, Fyrom // Arch. Biol. Sci. - 2010. - V. 62 (2). - P. 351-361.

8. Nowak D.J., Crane D.E., Stevens J.C. Air pollution removal by urban trees and shrubs in the United States // Urban Forestry and Urban Greening. - 2006. - № 4. - P. 115-123.

9. Yigit N. Determination of heavy metal accumulation in air through annual rings: the case of Malus floribunda species // Applied ecology and environmental research. - 2019. - V. 17 (2). P. 2755-2764.

10. Arsenic in tree rings at a highly contaminated site / Z . Cheng, B.M. Buckley, B. Katz, W. Wright, R. Bailey, K.T. Smith // Science of the Total Environment. - 2007. - № 376. - P. 324-334.

11. Kiss T., Fekete I., Tápai I. Environmental status of a city based on heavy metal content of the tree-rings of urban trees: case study at Szeged, Hungary // Journal of Environmental Geography. - 2019. - V. 12 (1-2). - P. 13-22.

12. Elements content in tree rings from $\mathrm{Xi}$ 'an, China and environmental variations in the past 30 years / Y. Liu, W. Ta P. Cherubini, R. Liu, Y. Wang, C. Sun // Science of the Total Environment. - 2018. - V. 619-620. - P. 120-126.

13. Geraldo S.M., Canteras F.B., Moreira S. Biomonitoring of environmental pollution using growth tree rings of Tipuana tipu: quantification by synchrotron radiation total reflection X-ray fluorescence // Radiation Physics and Chemistry. - 2014. V. 95. - P. 346-348.

14. Monitoring of the environmental pollution by trace element analysis in tree-rings using synchrotron radiation total reflection X-ray fluorescence / A.E.S. Vives, S. Moreira, S.M.B. Brienza, J.G.S. Medeiros // Spectrochimica Acta. - 2006. - № 61. P. $1170-1174$

15. Dynamic response of tree growth to changing environmental pollution / R. Juknys, A. Augustaitis, J. Vencloviene, A. Kliučius // European Journal Forest. - 2014. - № 133. - P. 713-724. можности восстановления истории прошлого загрязнения. Однако для установления химических элементовиндикаторов техногенного воздействия необходимы дальнейшие научные исследования и эксперименты.

16. Variations of tree ring width and chemical composition of wood of pine growing in the area nearby chemical factories / B. Sensuła, S. Wilczyński, L. Monin, M. Allan, A. Pazdur, N. Fagel // Geochronometria. - 2017. - № 44. - P. 226-239.

17. Oak tree-rings record spatial-temporal pollution trends from different sources in Terni (Central Italy) / A. Perone, C. Cocozza, P. Cherubini, O. Bachmann, M. Guillong // Environmental Pollution. - 2018. - V. 233. - P. 278-289.

18. Рихванов Л.П., Архангельская Т.А., Замятина Ю.Л. Дендрорадиография как метод ретроспективной оценки радиоэкологической ситуации. - Томск: Дельтаплан, 2015 - 148 с.

19. Drouet T., Herbauts J., Demaiffe D. Long-term records of strontium isotopic composition in tree rings suggest changes in forest calcium sources in the early 20th century // Global Change Biology. - 2005. - № 11. - P. 1926-1940.

20. Carbon isotope composition of atmospheric carbon dioxide in Southern Poland: imprint of anthropogenic $\mathrm{CO}_{2}$ emissions in regional biosphere / A. Pazdur, T. Kuc, S. Pawełczyk, N. Piotrowska, B.M. Sensuła, K. Różań-ski // Radiocarbon. 2013. - V. 55 (2-3). - P. 848-864.

21. Черненькая Е.В., Рихванов Л.П., Барановская Н.В. Плутоний в некоторых типах травянистой и кустарничковой растительности юга Западной Сибири // Фундаментальные исследования. - 2015. - № 2 (Ч. 5). - С. 984-991.

22. Новиков С.А. Мирные ядерные взрывы // Соросовский образовательный журнал. - 1999. - № 11. - С. 82-89.

23. Большунова, Т.С., Рихванов Л.П., Барановская Н.В. Элементный состав лишайников как индикатор загрязнения атмосферы // Экология и промышленность России. - 2014. № 11. - C. 26-31.

24. Мясников А.А. Современное формирование урановой осадочно-инфильтрационной (гидрогенной) минерализации Баргузино-Чивыркуйского перешейка на озере Байкал // Минералогия и геохимия ландшафта горнорудных территорий. Современное минералообразование: Труды II Всероссийского симпозиума с международным участием и VIII Bcepocсийских чтений памяти академика А.Е. Ферсмана. - Чита, 2008. - C. 93-96.

25. Методы дендрохронологии. Ч. І. Основы дендрохронологии. Сбор и получение древесно-кольцевой информации / С.Г. Шиятов, Е.А. Ваганов, А.В. Кирдянов, В.Б. Круглов, В.С. Мазепа. - Красноярск: КрасГУ, 2000. - 80 с.

26. Ковальский В.В. Геохимическая экология. - М.: Наука, 1974. $-302 \mathrm{c}$.

27. Кабата-Пендиас А., Пендиас Х. Микроэлементы в почвах и растениях. - М.: Мир, 1989. - 439 с.

28. Study of seasonal variations of trace-element concentrations within tree rings by thick-target PIXE analyses / L. Harju, J-O. Lill, K-E. Saarela, S-J. Heselius, F.J. Hernberg, A. Lindroos // Nuclear Instruments and Methods in Physics Research. - 1996. V. 109-110. - P. 536-541.

29. Оценка ущерба окружающей среде от загрязнения токсичными металлами / А.А. Головин, И.А. Морозова, Н.Г. Гуляева, Н.Я. Трефилова. - М.: ИМГРЭ, 2000. - 134 с.

30. Распределение радиоактивных элементов в окружающей среде Прибайкалья (Сообщение 1, Уран) / В.И. Гребенщикова, Н.А. Китаев, Э.Е. Лустенберг, В.И. Медведев, И.С. Ломоносов // Сибирский экологический журнал. - 2009. № 1. - С. 17-28. 


\section{Информация об авторах}

Миронова A.C., аспирант отделения геологии Инженерной школы природных ресурсов Национального исследовательского Томского политехнического университета.

Рихванов Л.П., доктор геолого-минералогических наук, профессор отделения геологии Инженерной школы природных ресурсов Национального исследовательского Томского политехнического университета.

Барановская Н.B., доктор биологических наук, профессор отделения геологии Инженерной школы природных ресурсов Национального исследовательского Томского политехнического университета.

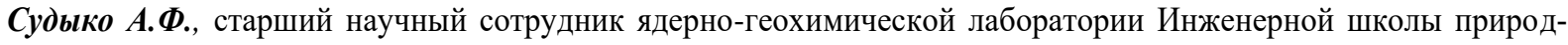
ных ресурсов Национального исследовательского Томского политехнического университета. 
UDC 550.47

\title{
ANNUAL RINGS OF SCOTS PINE (PINUS SYLVESTRIS L.) IS THE INDICATOR OF GEOCHEMICAL CONDITIONS AND CHRONOLOGICAL CHANGES IN CHEMICAL ELEMENTAL COMPOSITION OF THE ENVIRONMENT
}

\author{
Anastasia S. Mironova ${ }^{1}$, \\ asm2@tpu.ru \\ Leonid P. Rikhvanov1, \\ rikhvanov@tpu.ru \\ Natalia V. Baranovskaya", \\ nata@tpu.ru

\section{Alexander F. Sudyko1,} \\ sudykoAF@yandex.ru \\ 1 National Research Tomsk Polytechnic University, \\ 30, Lenin avenue, Tomsk, 634050, Russia.
}

The relevance of the research consists in the need to search for invention of accurate and informative indicator for ecological monitoring. The aim of the research is to study the features of chemical elements accumulation in annual rings of pine (Pinus sylvestris $L$.) of different areas of growth; evaluate the information content and accuracy of the annual rings of trees as an indicator of the environment state. Object: annual rings of Scots pine (Pinus sylvestris L.).

Methods: selection of ordinary pine cores; natural drying, separation of samples into time intervals, grinding of cores; quantitative instrumental neutron-activation method of analysis (28 chemical elements) for all samples; processing and analysis of empirical data by statistical methods.

Results. Chemical elemental composition of annual rings of Scots pine (Pinus sylvestris L.) was determined. The samples were selected in three regions of Russia: Tomsk region, Kemerovo region and the Republic of Buryatia. Comparison of chemical elemental composition of annual tree rings of different regions helped to see geochemical features of each territory separately. Specific elements for the Tomsk region tree were: $R b(0,5 \mathrm{mg} / \mathrm{kg})$, Cs $(0,01 \mathrm{mg} / \mathrm{kg}), B a(3 \mathrm{mg} / \mathrm{kg})$, Ce $(0,02 \mathrm{mg} / \mathrm{kg})$ and other. For wood of Kemerovo region: Fe (34 mg/kg), $\mathrm{Cr}(1 \mathrm{mg} / \mathrm{kg}), S b(0,002 \mathrm{mg} / \mathrm{kg})$, As $(0,01 \mathrm{mg} / \mathrm{kg}), \mathrm{La}(0,01 \mathrm{mg} / \mathrm{kg}), U(0,004 \mathrm{mg} / \mathrm{kg})$ and other. For wood from the Republic of Buryatia: $\mathrm{Br}$ (1 mg/kg), Sr (7 mg/kg), Ag (0,04 mg/kg), Au (0,001 mg/kg), Th (0,001 mg/kg) and other. Thus, the dendrogeochemical method of research can be used to assess the geochemical situation of the territory by the level of accumulation of chemical elements in the annual rings of the tree. The dynamics of chemical elements entering the annual rings allow us to study the history of transformation of chemical elemental composition of the environment. Thus, iron and chromium trends for Pinus sylvestris of Kemerovo region reflect the development of ferrous metallurgy, and trends $\mathrm{As}, \mathrm{Ag}, \mathrm{Cs}, \mathrm{Sb}, \mathrm{U}, \mathrm{Sm}$, Th and $\mathrm{Br}$ - the development of the coal industry in the region. Trends in alkali metals $R b, C s$, radioactive $U$ and rare earth elements $N d, S m$, Eu showed the intensity of the impact in different time intervals of the nuclear fuel cycle and other alleged sources on the environment of the Tomsk region. Dendrochemical monitoring can be used for studying local and global environmental changes and allows reconstructing the history of past contamination.

\section{Key words:}

Tree rings, scots pine (pinus sylvestris), geochemistry, dendrogeochemistry, instrumental neutron activation analysis.

\section{REFERENCES}

1. Ault W.U. Senechal R.G., Erlebach W.E. Isotopic Composition as a Natural Tracer of Lead in the Environment. Environmental Science \& Technology, 1970, no. 4, pp. 305-313.

2. Tout R.E., Gilboy W.B., Spyrou N.M. Neutron activation studies of trace elements in tree rings. Journal of Radioanalytical Chemistry, 1977, no. 37, pp. 705-715.

3. Rikhvanov L.P., Robertus Yu.V., Mironova A.S., Baksht F.B., Suduko A.F. Dendrogeochemical features fossil larch (Pazyryk) and modern larches of Mountain Altai. Bulletin of the Tomsk Polytechnic University. Geo Assets Engineering, 2017, vol. 328, no. 6, pp. 108-119. In Rus.

4. Robertus Yu.V., Rikhvanov L.P., Lyubimov R.V. Dendrochemistry indication of cross-border transfers of toxicants to the Altai territory. Bulletin of the Tomsk Polytechnic University, 2010, vol. 317, no. 1, pp. 173-177. In Rus.

5. Grachev A.M., Vaganov E.A., Levitt S., Panyushkina I.P., Chebykin E.P. Methodology for development of a 600-year tree-ring multi-element record for Larch from the Taimyr Peninsula, Russia. Journal of Siberian Federal University. Series: Biology, 2013, vol. 6, no. 1, pp. 61-72. In Rus.
6. Demakov Y.P., Shvetsov M.S., Talantsev V.I., Kalinin K.K. Dinamika soderzhaniya zolnykh elementov v godichnykh sloyakh starovozrastnykh sosen, proizrastayushchikh $\mathrm{v}$ poymennykh biotopakh [Dynamics of the content of mineral elements in tree rings of old-growth pine trees growing in riparian habitats]. Vestnik Margtu, 2011, no. 3, pp. 25-35.

7. Hristovski S., Melovski L. Radial patterns of 13 elements in the tree rings of beech trees from Mavrovo national park, Fyrom. Arch. Biol. Sci, 2010, vol. 62 (2), pp. 351-361.

8. Nowak D.J., Crane D.E., Stevens J.C. Air pollution removal by urban trees and shrubs in the United States. Urban Forestry and Urban Greening, 2006, no. 4, pp. 115-123.

9. Yigit N. Determination of heavy metal accumulation in air through annual rings: the case of Malus floribunda species. Applied ecology and environmental research, 2019, vol. 17 (2), pp. 2755-2764.

10. Cheng Z., Buckley B. M., Katz B., Wright W., Bailey R., Smith K.T. Arsenic in tree rings at a highly contaminated site. Science of the Total Environment, 2007, no. 376, pp. 324-334.

11. Kiss T., Fekete I., Tápai I. Environmental status of a city based on heavy metal content of the tree-rings of urban trees: case study at Szeged, Hungary. Journal of Environmental Geography, 2019, vol. $12(1-2)$, pp. 13-22. 
12. Liu Y., Ta W., Cherubini P., Liu R., Wang Y., Sun C. Elements content in tree rings from Xi'an, China and environmental variations in the past 30 years. Science of the Total Environment, 2018, vol. 619-620, pp. 120-126.

13. Geraldo S.M., Canteras F.B., Moreira S. Biomonitoring of environmental pollution using growth tree rings of Tipuana tipu: quantification by synchrotron radiation total reflection X-ray fluorescence. $R a$ diation Physics and Chemistry, 2014, vol. 95, pp. 346-348.

14. Vives A.E.S., Moreira S., Brienza S.M.B., Medeiros J.G.S. Monitoring of the environmental pollution by trace element analysis in tree-rings using synchrotron radiation total reflection $\mathrm{X}$-ray fluorescence. Spectrochimica Acta, 2006, no. 61, pp. 1170-1174.

15. Juknys R., Augustaitis A., Vencloviene J., Kliučius A. Dynamic response of tree growth to changing environmental pollution. European Journal Forest, 2014, no. 133, pp. 713-724.

16. Sensuła B., Wilczyński S., Monin L., Allan M., Pazdur A., Fagel N. Variations of tree ring width and chemical composition of wood of pine growing in the area nearby chemical factories. Geochronometria, 2017, no. 44, pp. 226-239.

17. Perone A., Cocozza C., Cherubini P., Bachmann O., Guillong M. Oak tree-rings record spatial-temporal pollution trends from different sources in Terni (Central Italy). Environmental Pollution, 2018, vol. 233, pp. 278-289.

18. Rikhvanov L.P., Arkhangelskaya T.A., Zamyatina L.Yu. Dendroradiografiya kak metod retrospektivnoy otsenki radioekologicheskoy situatsii [Dendroradiography as a method of retrospective evaluation of radioecological situation]. Tomsk, Deltoplan Publ., 2015. 148 p.

19. Drouet T., Herbauts J., Demaiffe D. Long-term records of strontium isotopic composition in tree rings suggests changes in forest calcium sources in the early 20th century. Global Change Biology, 2005, no. 11, pp. 1926-1940.

20. Pazdur A., Kuc T., Pawełczyk S., Piotrowska N., Sensuła B.M., Różań-ski K. Carbon isotope composition of atmospheric carbon dioxide in Southern Poland: imprint of anthropogenic $\mathrm{CO}_{2}$ emissions in regional biosphere. Radiocarbon, 2013, vol. 55 (2-3), pp. 848-864.

21. Chernenkaya E.V., Rikhvanov L.P., Baranovskaya N.V. Plutonium in some types of herbaceous and shrubby vegetation in the South of Western Siberia. Fundamental research, 2015, no. 2 (P. 5), pp. 984-991. In Rus.

22. Novikov S. A. Mirnye yadernye vzryvy [Peaceful nuclear explosions]. Soros educational journal, 1999, no. 11, pp. 82-89.
23. Bolshunova T.S., Rikhvanov L.P., Baranovskaya N.V. Elemental composition of lichens as an indicator of air pollution. Ecology and industry of Russia, 2014, no. 11, pp. 26-31. In Rus.

24. Myasnikov A.A. Sovremennoe formirovanie uranovoy osadochnoinfiltratsionnoy (gidrogennoy) mineralizatsii BarguzinoChivyrkuyskogo peresheyka na ozere Baykal [Modern formation of uranium sedimentary-infiltration (hydrogenic) mineralization, Barguzin-Chivyrkuisky isthmus in Lake Baikal]. Mineralogiya $i$ geokhimiya landshafta gornorudnykh territory. Sovremennoe mineraloobrazovanie: Trudy II Vserossiyskogo simpoziuma s mezhdunarodnym uchastiem $i$ VIII Vserossiyskikh chteny pamyati akademika A.E. Fersmana [Mineralogy and Geochemistry of landscape of the mining areas. Modern mineral formation: Proc. of the II allRussian Symposium with international participation and the VIII all-Russian readings of the memory of academician A.E. Fersman]. Chita, 2008. pp. 93-96.

25. Shiyatov S.G., Vaganov E.A., Kirdyanov A.V., Kruglov V.B., Mazepa V.S. Metody dendrokhronologii. Ch. I. Osnovy dendrokhronologii. Sbor i poluchenie drevesno-koltsevoj informatsii [Dendrochronology methods. P. I. Basics of dendrochronology. Collection and receipt of tree-ring information]. Krasnoyarsk, KrasSU Publ., 2000. 80 p.

26. Kovalsky V.V. Geokhimicheskaya ekologiya [Geochemical ecology]. Moscow, Nauka Publ., 1974. 302 p.

27. Kabata-Pendias A., Pendias H. Mikroelementy v pochvakh i rasteniyakh [Trace elements in soils and plants]. Moscow, Mir Publ., 1989. $439 \mathrm{p}$.

28. Harju L., Lill J-O., Saarela K-E., Heselius S-J., Hernberg F.J., Lindroos A. Study of seasonal variations of trace-element concentrations within tree rings by thick-target PIXE analyses. Nuclear Instruments and Methods in Physics Research, 1996, vol. 109-110, pp. 536-541.

29. Golovin A.A., Morozova I.A., Gulyaeva N.G., Trefilova N.I. Otsenka ushcherba okruzhayushhey srede ot zagryazneniya toksichnymi metallami [Assessment of damage to the environment from contamination with toxic metals]. Moscow, IMGRE Publ., 2000. $134 \mathrm{p}$.

30. Grebenshchikova V.I., Kitaev N.A., Lustenberg E.E., Medvedev V.I., Lomonosov I.S. Distribution of radioactive elements in the environment of the Baikal region (Message 1, Uranium). Contemporary Problems of Ecology, 2009, no. 1, pp. 17-28. In Rus.

Received: 3 April 2019.

\section{Information about the authors}

Anastasia S. Mironova, postgraduate, National Research Tomsk Polytechnic University.

Leonid P. Rikhvanov, Dr. Sc., professor, National Research Tomsk Polytechnic University.

Natalia V. Baranovskaya, Dr. Sc., professor, National Research Tomsk Polytechnic University.

Alexander F. Sudyko, senior researcher, National Research Tomsk Polytechnic University. 